\title{
EL TÓPICO DE LO POSITIVO \\ FRENTE A LO NEGATIVO EN ISLAS DEL ATLÁNTICO
}

\author{
Fremiot Hernández González - Juan F. Hernández Benayas \\ Universidad de La Laguna \\ fhernand@ull.edu.es - jfremiot@hotmail.com
}

\begin{abstract}
RESUMEN
Un relato que muchas veces ha llamado la atención no solo de los estudiosos sino también de los lectores es el de las dos fuentes, dos ríos o dos tipos de árboles que producen agua o líquido con propiedades opuestas. En este artículo se hace un repaso y se analizan algunos pasajes de textos principalmente griegos y latinos en los que aparece este fenómeno referido a algunas islas del Océano Atlántico.

Palabras Clave: Textos griegos, Textos latinos, Leyendas, Fortunatae Insulae, Geografía.
\end{abstract}

THE TOPIC OF THE POSITIVE VERSUS THE NEGATIVE IN ATLANTIC ISLANDS

\section{ABSTRACT}

A story that has often attracted the attention not only of researchers but also of readers is that about two sources, two rivers or two types of trees that produce water or liquid with opposite qualities. This paper reviews and analyses some passages of mainly Greek and Latin texts in which this phenomenon appears referring to some islands of the Atlantic Ocean.

KeYwOrDs: Greek Texts, Latin Texts, Legends, Geography, Fortunatae Insulae.

\section{INTRODUCCIÓN}

Con relativa frecuencia nos encontramos con que en muchos islarios y mapas se mencionan o dibujan islas tanto reales como imaginarias o fabulosas de las que se relata o en las que aparecen representados algunos lugares comunes, a menudo inverosímiles, cuyo origen es desconocido, pero que probablemente tienen su base en algo real. En este artículo nos vamos a fijar en un tópico que podemos llamar «de lo bueno frente a lo malo» o «de lo positivo en contraposición con lo negativo», y lo vamos a estudiar en unas islas del Océano Atlántico que aparecen en la cartografía y en textos de distintos autores.

A lo largo de su historia los mapas y portulanos, sobre todo a partir de la Edad Media, están llenos de lugares, principalmente islas en los mares, que aparecen en una edición y desaparecen en la siguiente, incluso cambian de sitio, porque 
los cartógrafos que los confeccionaron se fiaron de los textos e informaciones de los autores antiguos y plasmaron en sus cartas geográficas lo que estos transmitieron, fiándose exclusivamente de la autoridad del escritor, generalmente griego (Heródoto, Hiparco, Ptolomeo, etc.), romano (Pomponio Mela, Plinio el Viejo, etc.) o árabe (Ibn-Hawqal, Al-Idrisi, etc.), pues no tenían la posibilidad de contrastar la información; mas cuando los exploradores y marineros intentaron visitar esos lugares, no los encontraron. A nosotros nos interesan en este momento las islas que, siguiendo una denominación ya clásica, se suelen denominar «fantasma».

\section{LAS «ISLAS FANTASMA»}

El tema de las islas "fantasma» o islas inventadas es bastante antiguo, pues como dice Tallack (2016: 20), «For as long as people have been making stories, they have been inventing islands. In literature and in legend, they are there from the very start». Efectivamente, los antiguos griegos fueron uno de esos pueblos que inventaron islas: no hay más que acudir a la Ilíada y a la Odisea para encontrar islas imaginadas en las que se sitúan múltiples leyendas. Es en el Océano Atlántico en donde aparece el mayor número de este tipo de islas, probablemente porque fue el lugar durante mucho tiempo más inexplorado y porque a los antiguos les resultaba demasiado conocido y transitado el Mare Nostrum como para imaginarse en él islas al margen de la historia y del tiempo ${ }^{1}$. Ya en la Antigüedad son muchos los que hablan

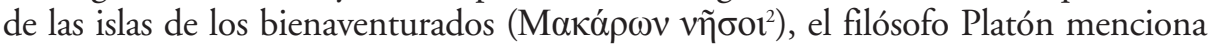
la Atlántida situándola «más allá de las columnas de Hércules», esto es, en el Océano,

${ }^{1}$ Cf. García y Bellido, 1967: 9.

${ }^{2}$ El primero que utiliza esta expresión es Hesíodo: hablando de las distintas razas de hombres

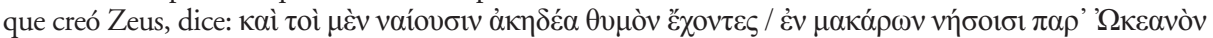

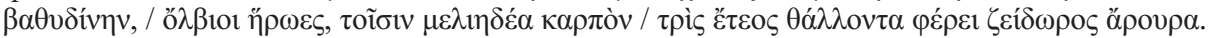
'Y estos habitan, con el ánimo sin preocupaciones, en las islas de los bienaventurados en el profundo Océano, héroes felices, para quienes la tierra fructífera produce tres veces al año frutos dulces como la miel' (Hesiodi Theogonia, Opera et Dies, Scutum, ed. Friedrich Solmsen; Fragmenta Selecta, edd. R. Merkelbach et M. L. West, Oxford 1970, vv. 170-174). Ya Isaac Voss nos señaló autores y lugares en los que podemos encontrar referencias a las Islas de los Bienaventurados cuando, después de hablar

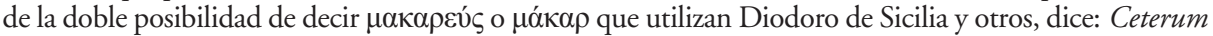

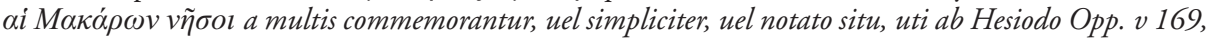
Platone in Menex. haud procul ab in. Herodoto 3,26, Strabone 3, p. 104, f. 150, Pindaro Olympic. 2,129, Euripide in Helena v. 1693, Apollodoro 3, 10, 1, Lycophr. v. 1204, copiose ad Tzetze ad Hesiod. Opp. v. 169, p. m. 50 et aliis. Y añade: Poetae qui in iis beatorum sedes et Elysium constituunt, ad Oceanum ponunt, at in situ uarie discrepant (En Pomponii Melae de situ orbis libri tres ad plurimos codices manuscriptos uel denuo uel primum consultos aliorumque editiones recensiti cum notis criticis et exegeticis uel integris uel selectis Hermolai Barbari,... Is. Vossii, ... conlectis praeterea et adpositis doctorum uirorum animaduersionibus, additis suis a Carolo Henrico Tzschuckio... Leipzig 1806-1807, 7 vols. [vol. III, pars II [1806], pp. 583-584]). 
y el geógrafo Piteas describe la isla de Tule ubicada muy al norte del mismo mar. Pero los propios antiguos pusieron en duda la existencia de estas islas como se puede leer en Estrabón y Polibio respecto a la Tule de Piteas. En efecto, Estrabón hablando de la opinión que tiene Polibio, historiador griego de la época helenística, sobre Piteas ${ }^{3}$ y sobre su descubrimiento dice en su Geografía, 1.2,4,14:

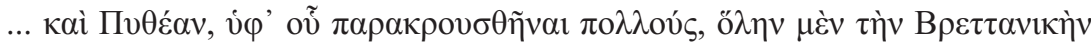

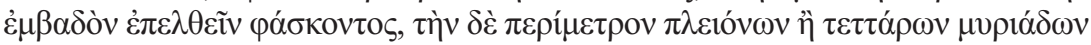

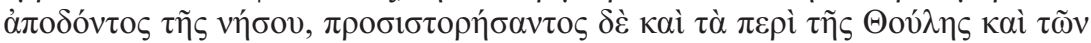
$\tau$

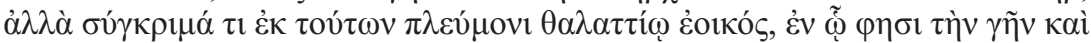

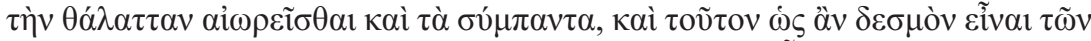

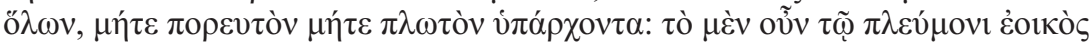

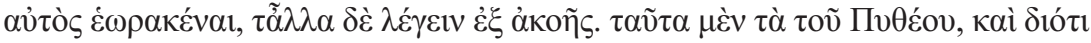

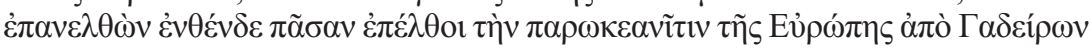

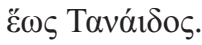

(Dejo a un lado) también a Piteas, por quien muchos fueron engañados, cuando afirmó que había recorrido a pie toda Britania, y atribuyendo un perímetro a la isla de más de 40.000 estadios, habiendo hecho relatos también sobre Tule y aquellos lugares en los que no se encuentra ya ni tierra propiamente dicha, ni mar, ni aire, sino un compuesto de estos, semejante a un pulmón marino ${ }^{5}$ en el que dicen que la tierra y el mar y todo está en suspensión, y esto es como un vínculo de todos, sin acceso ni a pie ni navegable. Lo semejante a un pulmón él mismo lo vio, pero las otras cosas las dice de oídas. A estas cosas de Piteas (Polibio) añade también que regresando de allí (Piteas) recorrió todo el litoral oceánico de Europa desde Gadir hasta Tanais.

Pero donde Estrabón se despacha a gusto y da su propia opinión sobre Piteas y la isla es en 4,5,5 con estas palabras:

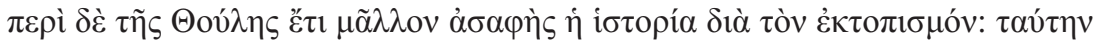

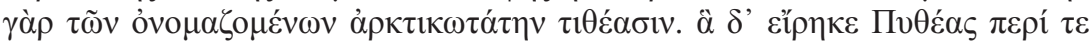

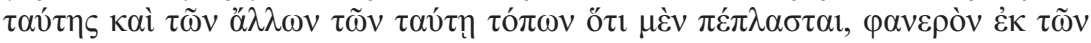

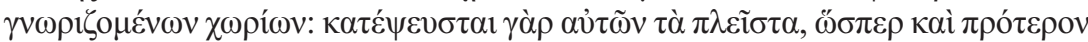

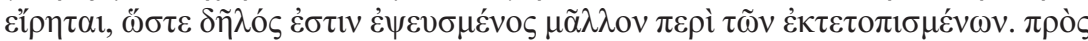

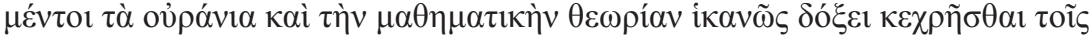

${ }^{3}$ Polibio nos dice que Piteas era hermano de Acates e hijo de Cleomenes. Al principio no tenía buenas costumbres, pero la gente se hacía la ilusión de que esto era un vicio de juventud y que con el tiempo se reformaría. Sin embargo, cuando tuvo a su cargo los cuidados del gobierno no cambió de conducta, teniendo siempre la misma avidez y las mismas ansias de enriquecerse.

${ }^{4}$ Los textos en griego de Estrabón los hemos cogido de la edición de Meineke (1867).

5 'Especie de molusco', 'medusa'. 


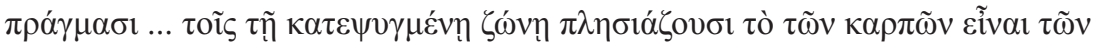

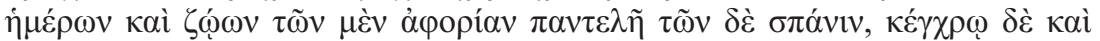

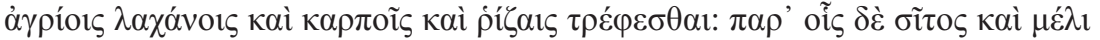

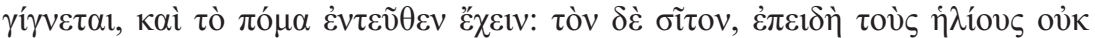

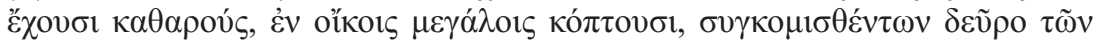

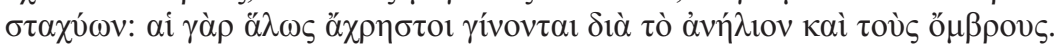

En cuanto a Tule la información es todavía más desdibujada debido a la distancia, pues sitúan a esta como la más al norte de las nombradas; que lo que dijo Piteas sobre esta y sobre los lugares que hay en esta fue una invención aparece claro partiendo de lo que dijo sobre las regiones que nos han llegado a ser conocidas, pues dijo mentiras de la mayor parte de estas, como ya se dijo antes, de modo que está claro que mintió más sobre regiones remotas. Sin embargo, parece que acomodó adecuadamente sus afirmaciones a la astronomía y a la teoría matemática... Los que están cerca de la zona glacial tienen carencia de frutos cultivados, y de unos animales domésticos tienen carencia total, y de otros escasez; se alimentan de mijo, hierbas y frutos silvestres y raíces; los que tienen trigo y miel, también obtienen de ello la bebida; el trigo, puesto que no tienen sol despejado, lo trillan en grandes silos después de haber llevado allí las espigas, pues las eras son inútiles debido a la falta de sol y de lluvia.

Aunque es a partir del Medievo cuando las islas «fantasma» más frecuentemente aparecen en los mapas lógicamente y en los textos literarios, sin embargo, nuestra época, a pesar de la existencia de una serie de medios técnicos como son los radares, satélites, buques de investigación, etc., no se ha visto libre de este tipo de islas que figuran incluso en los mapas. Sin ir más lejos, situada al sur del Océano Pacífico, concretamente en aguas de Nueva Caledonia, la Isla Sandy fue mencionada por primera vez en la Chart of discoveries made in the South Pacific Ocean in his Majesty's ship Resolution under the command of Captain Cook. 1774, y se reflejó en muchos mapas desde finales del s. XIX hasta el año 1979, e incluso después. Pero resultó ser un error, fruto probablemente de una ilusión óptica, es decir: una isla "fantasma». Con todo, sabemos que ha habido islas intencionadamente inventadas para lograr algún fin, generalmente de tipo económico: tal es el caso, por ejemplo, de la llamada Crocker Land, inventada por el explorador norteamericano Robert Edwin Peary con el fin de lograr el apoyo financiero del magnate George Crocker.

Como señala Babcock (1922: 1), no estamos en condiciones de decir a partir de qué momento los hombres que habitaban la cuenca del Mediterráneo oriental se aventuraron por primera vez a lanzarse a través del Estrecho de Gibraltar al mar abierto, ni siquiera cuándo permitieron por primera vez dar rienda suelta a sus fantasías para seguir el mismo camino e imaginar islas en el gran misterio occidental. «Probablemente ambos eventos ocurrieron no mucho después de que estos hombres desarrollaron suficiente competencia en la navegación para alcanzar el límite occidental del Mediterráneo. Igualmente, carecemos de un conocimiento positivo sobre qué nación marinera abrió el camino».

Hay consenso, sin embargo, en admitir que los primeros conocimientos reales de lo que había en el Mar Hesperio de los antiguos o Mar Tenebroso o de Tinieblas, como lo llamaron, entre otros, los árabes, se debe a los fenicios y que se produjo 
probablemente antes del 1100 a. de Cristo ${ }^{6}$, pero ellos, lo mismo que después los cartagineses, no tuvieron ningún interés en difundir sus averiguaciones, ya que consideraban la zona un reducto suyo y les interesaba intimidar a los navegantes extranjeros para que no penetraran en ese mar (Martínez Hernández, 1992: 33)7. Pero, aunque la realidad de los viajes griegos al otro lado del Estrecho de Gibraltar no se produjo hasta el momento en que empezó a decaer el poderío cartaginés (Jorge Godoy, 1996: 74-75), sin embargo los griegos ya desde la época heroica se habían hecho una idea de lo que podría haber detrás de las Columnas de Hércules. El episodio que cuenta Teopompo y recoge Eliano es revelador:

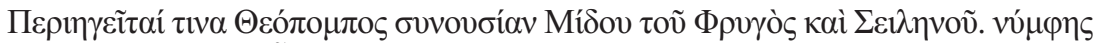

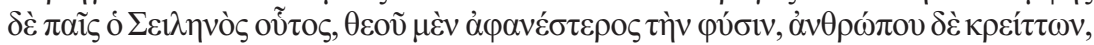

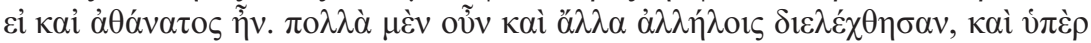

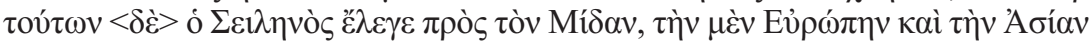

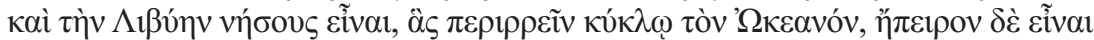

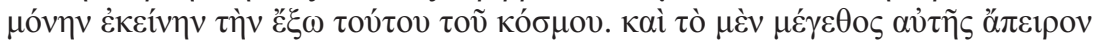

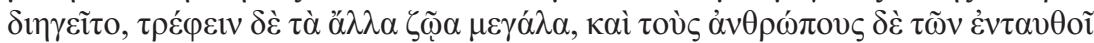

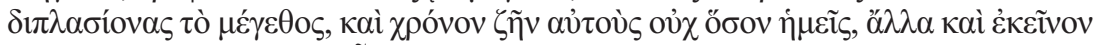

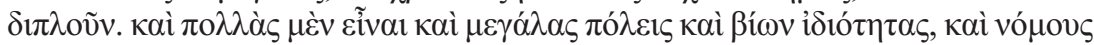

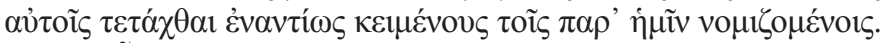

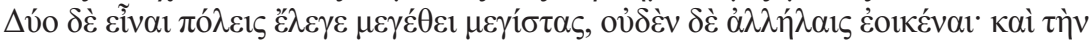

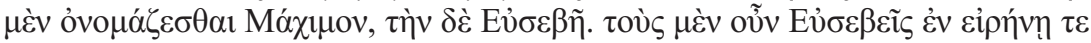

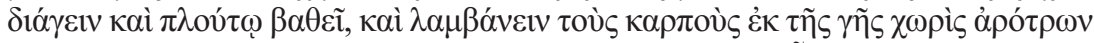

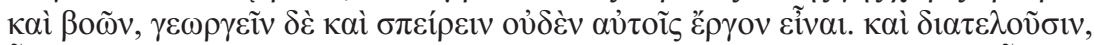
$\tilde{\eta} \delta$ 'ö

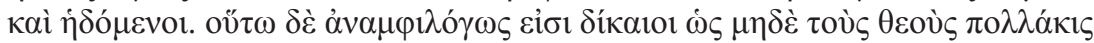

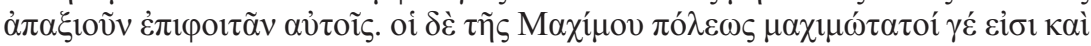

${ }^{6}$ Esto no significa que los fenicios visitaran en esta época las denominadas Fortunatae Insulae o, si se quiere, las Islas Canarias, pues como dice J. J. da Costa Macedo, «Quando digo que os Phenicios e Carthaginezes não tiverão conhecimento das Canarias, quero que se entenda que não ha monumentos historicos escriptos que tal nos afiancem; e que, por consequencia, nenhum raio de luz nos reflectio delles, que possa alumiarnos em semelhante materia» (Macedo, 1843: 50).

${ }^{7}$ Recordemos que Diodoro de Sicilia dice que los fenicios al principio comunicaron su descu-

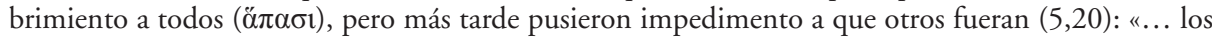
fenicios se habían dado a la mar para explorar ... la costa situada fuera de las Columnas de Hércules, y mientras navegaban a lo largo de la costa de Libia, fueron arrojados por fuertes vientos muy lejos en el Océano. Golpeados por la tempestad durante muchos días, finalmente llegaron a la isla de la que hemos hablado. Habiendo conocido la riqueza del suelo, comunicaron su descubrimiento a todos. Por eso a los etruscos, poderosos en el mar, cuando querían enviar también una colonia a esta isla, los cartagineses se lo impidieron. Estos últimos temían, por un lado, que demasiados de sus conciudadanos, atraídos por la belleza de esta isla, desertaran de su patria. Por otro lado, lo veían como un refugio adonde podrían retirarse en caso de que alguna desgracia le sucediera a Cartago. Porque esperaban que siendo dueños del mar, podrían trasladarse con todas sus familias a esta isla que sería ignorada por sus vencedores». Para el texto griego cf. Oldfather (1989). 


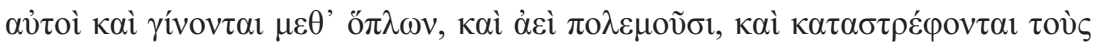

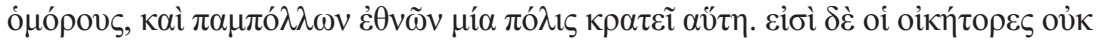

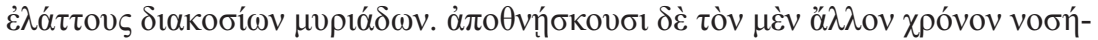

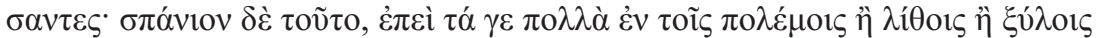

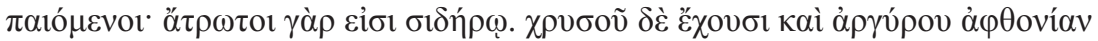

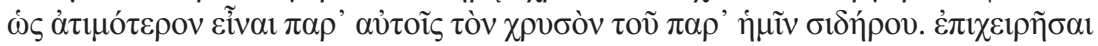

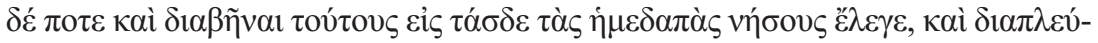

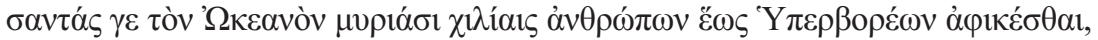

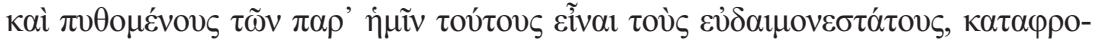

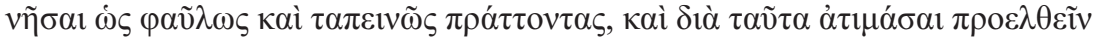
$\pi \varepsilon \rho \alpha \imath \varepsilon \dot{\varepsilon} \rho \omega(3,18)^{8}$.

Teopompo relata con detalle una conversación entre el frigio Midas y Sileno. Este Sileno era hijo de una ninfa; por su naturaleza era inferior a los dioses aunque superior a los hombres, puesto que era inmortal. Conversaron sobre los más diversos asuntos, pero en concreto esto fue lo que Sileno le dijo a Midas. Europa, Asia y Libia son islas en torno a las que fluye, en círculo, el Océano, y hay un continente que está fuera de nuestro mundo. Le explicó minuciosamente su ilimitada grandeza y le contó que ese continente genera enormes animales y que los hombres que allí viven nos doblan en estatura. Su tiempo de vida no es como el nuestro, sino el doble. Tienen muchas y grandes ciudades y diversas formas de vida. Allí se han promulgado leyes que son absolutamente opuestas a las que están vigentes entre nosotros.

Decía Sileno que las ciudades más grandes son dos, pero que en nada se parecen entre sí. Una de ellas se llama Guerrera y la otra Pía. Los habitantes de Pía viven en paz y opulencia, obtienen los frutos de la tierra sin arados ni bueyes, y no tienen necesidad ni de trabajar la tierra ni de sembrar. Viven, continuaba Sileno, sanos y, sin conocer la enfermedad, llegan al final de sus días, llenos de gozo y alegría. Tan indiscutiblemente justos son que ni siquiera los dioses tienen por indigno visitarlos con frecuencia. En cambio, los habitantes de la ciudad Guerrera son muy belicosos, nacen con las armas en las manos. Siempre están en guerra, sometiendo a los pueblos vecinos. Y así, esa ciudad, sola, domina numerosísimos pueblos. Sus habitantes no son menos de veinte millones. En ocasiones mueren enfermos, aunque raramente, puesto que en la mayoría de las ocasiones pierden la vida en sus guerras, heridos por piedras y maderos, ya que son invulnerables al hierro. Tanto abunda el oro y la plata que el oro vale tan poco para ellos como el hierro para nosotros. Decía Sileno que en cierta ocasión intentaron cruzar hasta las islas de nuestro mundo, atravesando el Océano, con una fuerza de diez millones de hombres. Llegaron hasta los hiperbóreos y cuando comprendieron que eran los hombres más dichosos de nuestro mundo los despreciaron por considerar su forma de vida insignificante. Por esta razón desistieron de continuar su avance (Cortés Copete, 2006: 107-108).

${ }^{8}$ Los textos griegos de Eliano los tomamos de la edición de Dilts (1974).

${ }^{9}$ Para esta traducción el autor de la misma ha seguido el texto griego de la mencionada edición de M. R. Dilts. 
Lo que aquí relata Teopompo es extraordinario, tanto que el propio Eliano se sorprende y es consciente de que a algunos les podría parecer inverosímil. Por eso

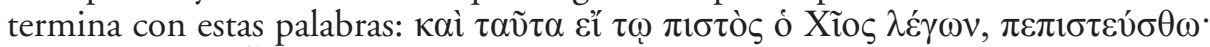

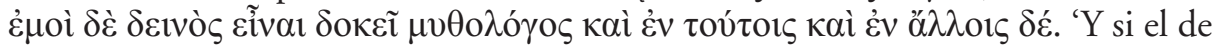
Quíos $^{10}$ al contar estas cosas es creíble para alguno, créalo: a mí me parece que es un mitólogo excelente no sólo en esta ocasión sino también en otras'.

Por lo demás, hay que tener en cuenta que muchas de las islas que en un momento determinado fueron consideradas como islas "fantasma», más tarde han podido ser identificadas con islas reales que ya existían; incluso a veces, sobre todo en época más reciente, se ha podido determinar que lo que se consideraba como una isla era solamente un iceberg. A este propósito conviene recordar la identificación de las islas estudiadas por él que William H. Babcock hace en el capítulo 13 de su libro, en el apartado que él denomina «Summary» (Babcock, 1922: 187-188). Sobre la isla Brasil ${ }^{11}$ dice que «Probablemente representa la región alrededor del Golfo de San Lorenzo, traída en el mismo paralelo indebidamente cerca de la costa irlandesa». Sobre la isla Man o Mayda, se inclina a pensar que se trata de las Bermudas o de algún punto sobresaliente en la costa de los EEUU, aunque hay unos indicios que la conectan con los bretones, pero otros con los árabes. Respecto a la isla de las Siete Ciudades ${ }^{12}$ piensa Babcock que pudo haber sido la isla San Miguel de las Azores -allí hay un valle con su nombre-, a pesar de que durante mucho tiempo se confundió con Antilia. En relación con el grupo o serie de cuatro islas de las Antillas que aparecen en el Mapa de Beccario de 1435, él identifica Antilia ${ }^{13}$ con Cuba, Reylla con Jamaica,

el año 380 a. C.
${ }^{11}$ La primera vez que aparece esta isla en un mapa es en el Atlas Medicis de 1351. Curiosamente en el mapa de Pizigani de 1367 hay tres islas con este nombre en el Océano Atlántico: una está situada al noroeste del Cabo de San Vicente, con el nombre de Braçir, y las otras dos al oeste de Irlanda, una con el mismo nombre y la otra, más al norte, con la denominación de Insula de Mayotas seu de Braçir.

${ }^{12}$ Ver nota siguiente.

${ }^{13}$ Esta isla aparece dibujada en una serie de mapas a partir de 1424. En el de Andrea Bianco de 1436 está situada al oeste de la primera isla Braçir que hemos mencionado en la nota 10. En el globo de Martín Behaim de 1492 también aparece y tiene la siguiente leyenda: «Por el año 734 después del nacimiento de Cristo, cuando la España entera fue invadida por los incrédulos de África, entonces también la isla de Antilia, llamada Septe citade (Siete Ciudades), arriba figurada, fue poblada por un arzobispo de Oporto (Portugal), con otros seis obispos y otros cristianos, hombres y mujeres, los cuales habiendo huido de España con sus bajeles, llegaron a ella con sus ganados y su fortuna. Por una casualidad, se acercó mucho allá en el año 1414 una nave de España» (Avezac, 1846: 139). De la misma fuente parece haber bebido Pedro de Medina para confeccionar parte del cap. 52, que titula «De las islas de Canaria e isla de la Madera y de la isla Antilia» (Medina, 1549: fols. 43r. -47v.). En fol. 47v. dice así: "Antilia, que agora no se vee. Esta isla halle yo figurada en una carta de marear muy antigua y como della no se tenga ninguna noticia, propuse buscar por muchas vias si della hallaria alguna razon o escriptura y en un Ptolomeo que fue dirigido al papa Urbano hallé señalada esta dicha isla y junto a ella escripto lo siguiente: «Ista insula Antilia aliquando a Lusitanis est inuenta, sed modo quando quaeritur non inuenitur. Inuentae sunt in illa gentes quae Hispanica lingua loquuntur. Quae tempore regis Roderici 
Salvagio o Satanaxio con Florida, e I in Mar es una o más de las Bahamas, pues posiblemente esta expresión I in Mar sea 'Isla en el Mar' y aludía a 'Islas Marinas' en general y no a una de ellas en particular.

Con todo, no se puede perder de vista la posibilidad de que haya islas que en un momento determinado se hayan sumergido en el mar, pues del mismo modo que han surgido pueden ser absorbidas, aunque bien es verdad que este fenómeno no se produce de un día para otro y lo normal es que el proceso de desaparición se realice a lo largo de millones de años: la geocronología nos da buena cuenta de ello. En época histórica ha habido desapariciones de islas: es cierto que generalmente se trata de pequeñas islas -hay excepciones-, arrecifes de baja altitud o atolones que son sumergidos por el aumento del nivel del mar y por la erosión ${ }^{14}$, incluso hay islas que se han desintegrado debido a erupciones volcánicas y se las ha tragado el mar. A pesar de ello, para nuestro estudio proponemos dar por bueno que esas islas que aparecían en mapas medievales o renacentistas o en los textos de autores antiguos y medievales y que después no fueron encontradas, eran islas "fantasma».

\section{EL TÓPICO DE LAS DOS AGUAS}

La presencia del tema de dos aguas que brotan ordinariamente de dos fuentes distintas - a veces de una sola- o corren por dos cauces diferentes es antigua en la literatura griega y aparece ya desde Homero. Concretamente en la Odisea, cuando el poeta está describiendo el palacio de Alcínoo, al que había llegado Odiseo conducido por Atenea bajo la apariencia de una niña pequeña con un ánfora, después de cantar sus

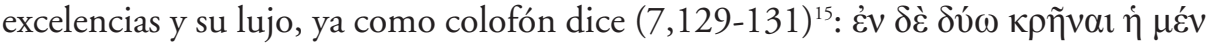

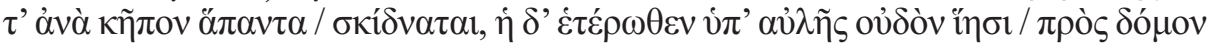

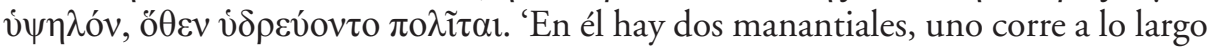
de toda la huerta; el otro va hacia la excelsa morada y sale de la casa por debajo del patio, en donde se aprovisionan de agua los ciudadanos'. Aunque está claro que un manantial sirve para regar la huerta, y el otro para consumo humano, no por ello tenemos que deducir que uno es de agua mala (el de regar) y el otro de agua buena,

\footnotetext{
qui ultimus Hispaniam tempore Ghothorum rexit, ad hanc insulam a facie Barbarorum qui tunc Hispaniam inuaserant, fugisse creduntur. Habent hic unum archiepiscopum cum sex aliis episcopis, at quilibet illorum suam habet propriam ciuitatem, quare a multis Insulam Septem Ciuitatum dicitur. Hic populus christianissime uiuit, omnibus diuitiis saeculi huius plenus». Añade que, según el mapa, la isla tiene 87 leguas de largo por 28 de ancho, y «figurados por toda ella muy buenos puertos y ríos». Efectivamente, la leyenda dice que los siete obispos reclutaron en torno a cinco mil feligreses y equiparon una flota de veinte barcos con el fin de huir de la invasión de los musulmanes. También se confunde esta isla con la «Isla de San Brendán» o de "San Borondón», nombre usual en Canarias.

${ }^{14}$ Bien estudiado y con perspectivas del futuro por Albert (2016).

${ }^{15}$ Los textos de Homero los hemos tomado de la edición de Allen (1962), tomo III.
} 
es decir, potable, pero tampoco podemos descartarlo, pues Homero no dice nada sobre las características de cada uno.

Una pareja de corrientes de agua de tipologías distintas y ya contrapuestas -aunque no enfrentadas desde el punto de vista de la salud- aparece en un pasaje de Platón referido a la Atlántida en el que Critias dice que Neptuno fortificó la colina en donde vivía Clito, su esposa, con una serie de muros, fosos de agua, etc. haciendo una especie de isla dentro de otra isla -la Atlántida-, y afirma (113e ${ }^{16}$ :

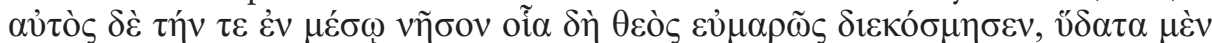

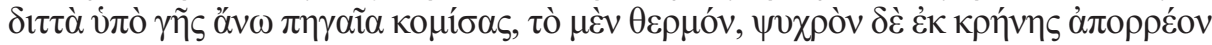

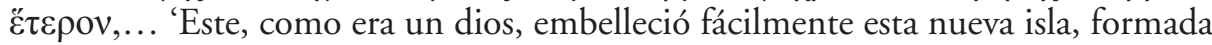
en medio de la otra, sacando de debajo de la tierra dos manantiales de agua, uno que fluía caliente y otro frío'.

Pero el tópico más frecuente es que en las islas tanto «fantasma» como geográficamente existentes, de los dos tipos de agua, uno produce beneficios frente al otro que es perjudicial. Lo vamos a ver en autores antiguos y medievales, griegos y latinos, y lo vamos a llamar el «tópico».

\subsection{El tópico en EL RELATO de TeOpompo}

Casi todo el relato de la conversación entre Midas y Sileno que nos ha conservado Eliano y que acabamos de ver es un contraste entre lo positivo y lo negativo, pero queremos hacer hincapié en el siguiente pasaje referido a la isla de los meropes, en donde Teopompo refiere el tópico de los dos tipos de agua: un agua salutífera frente a un agua perniciosa:

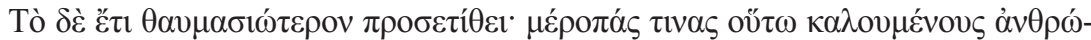

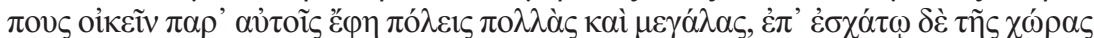

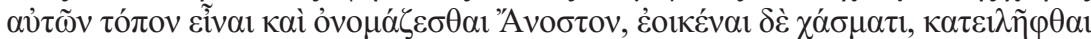

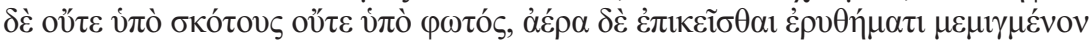

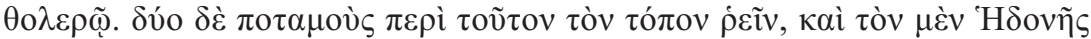

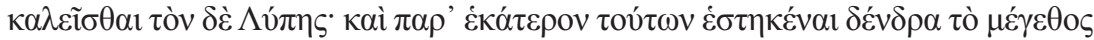

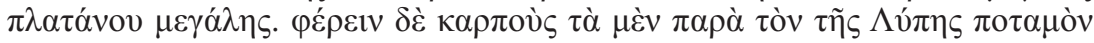

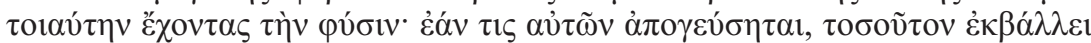

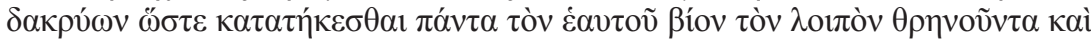

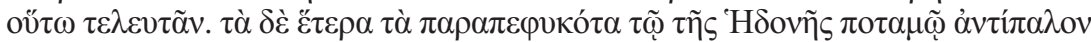

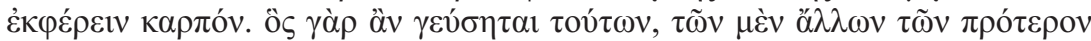

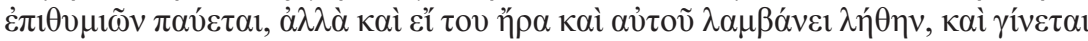

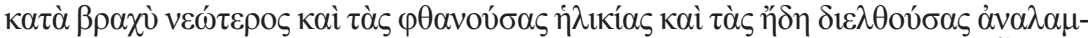

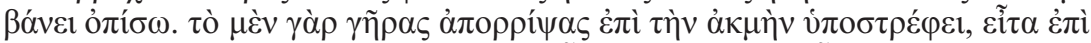

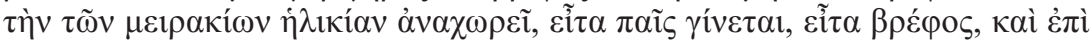

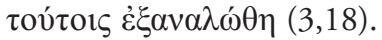

${ }^{16}$ Los textos de Platón los hemos tomado de la edición de Burnet (1957), tomo IV. 
Añadió un detalle todavía más sorprendente. Decía que ciertos hombres, llamados «meropes», habitan muchas y grandes ciudades, y que en el borde de su territorio hay un lugar llamado «Sin retorno». Tiene el aspecto de una sima. No está ocupado ni por las tinieblas ni por la luz, sino que sobre él flota como una neblina enrojecida, unida a cierta turbulencia. Dos ríos corren por esta región, uno llamado Placer, el otro, Dolor. En las orillas de cada uno de estos ríos hay árboles del tamaño de grandes plátanos. Los árboles que crecen junto al río Dolor producen frutos de la siguiente naturaleza. Si alguien los prueba, deja caer tantas lágrimas que consume todo el resto de su vida, hasta la muerte, en lamentos. Los otros árboles, los que han crecido junto al río Placer, producen frutos de características opuestas. Pues quien los prueba, cesa en todos sus anteriores deseos e, incluso si amaba a alguien, también de esa persona se olvida. Se va volviendo poco a poco más joven y va recuperando, hacia atrás, el tiempo que ya había vivido y aquellas edades por las que atravesó. Y así, tras abandonar la vejez, retorna a la madurez y, después, a la juventud para, a continuación, convertirse en un niño y después en un recién nacido. Tras todo ese recorrido, se consume (Cortés Topete, 2006: 109-110).

En este caso no es directamente el líquido elemento lo que refleja el contraste positivo frente al negativo, sino los frutos de los árboles que son regados por las aguas de los ríos Placer y Dolor, y que cuando son comidos por los habitantes del lugar, les producen los beneficios o perjuicios que proceden de la calidad del agua con la que la naturaleza los riega.

\subsection{El TÓPICO EN LAS FORTUNATAE INSULAE}

En los textos antiguos y renacentistas que nos han quedado referidos a las llamadas Islas Afortunadas o Islas de los Afortunados nos aparece el tópico del agua buena frente al agua mala. Nos vamos a fijar en Pomponio Mela y en Plinio el Viejo autores del siglo I d.C. que fallecieron con una diferencia de 34 años (Mela murió en 45 d.C. y Plinio en el 79 d.C.), así como en Julio Solino, probablemente del IV d.C., en Domenico Silvestri, del Trecento italiano, y en Lucio Marineo Sículo, historiógrafo de los Reyes Católicos.

\subsubsection{El tópico en la Chorographia de Pomponio Mela}

En la obra del hispanorromano Pomponio Mela titulada De Chorographia o De situ orbis aparece casi al final una breve alusión a las Islas Afortunadas, respecto a las que dice $(3,87)$ :

Contra Fortunatae insulae abundant sua sponte genitis et, subinde aliis super alia innascentibus, nibil sollicitos alunt beatius quam aliae urbes excultae. Vna singulari duorum fontium ingenio maxime insignis: alterum qui gustauere risu soluuntur in mortem; ita adfectis remedium est ex altero bibere.

En frente (del monte Atlas) las Islas Afortunadas abundan en frutos nacidos de forma espontánea y, naciendo unos detrás de otros, alimentan a sus habitantes nada preocupados más felizmente que otras ciudades cultivadas. Una (isla) es extremadamente 
famosa por la singular naturaleza de dos fuentes: los que toman de una se van debilitando debido a la risa hasta la muerte: a los de este modo afectados les sirve de remedio beber de la otra.

Para Mela los únicos hechos a destacar de estas Islas Afortunadas son que sus habitantes se alimentan de lo que produce la tierra sin necesidad de cultivarla y los dos tipos de fuentes. El fenómeno extraordinario de estas dos fuentes ha llamado la atención en todas las épocas y algunos lo han tomado como una especie de broma del autor. En el siglo XVI, por ejemplo, André Thevet, un viajero que pasó dos veces por el Archipiélago Canario y por supuesto leyó a Mela, se sorprende tanto de este relato que expresa con cierta sorna:

Pomponio Mela dice que hay dos fuentes, vecina una de otra, cuyo natural es admirable y no sin causa, si lo que cuenta fuese verdadero; una de ellas, si alguien bebe de ella le induce a reír de tal manera que es el último de sus pasatiempos si no se le da rápidamente de la otra... no me sorprendería de estas fuentes citadas por Mela, si dijese en qué isla de las Afortunadas están, pero es imposible que los modernos, que son tan curiosos y que han leído sus libros no hayan hecho toda diligencia para asegurarse de la verdad de una cosa tan notable... Si se quiere que otorgue fe a lo que él cuenta, hace falta que se me dé una razón a cambio, que sea un poco más sólida; dado que en su tiempo no había ninguna de estas islas que estuviese descubierta,... Si estas fuentes estaban en Canarias puede ser que fuese en un lugar tan oculto que nadie entró nunca salvo él, que nos las fantaseó así... (Aznar Vallejo, 1988: 860-861).

\subsubsection{El tópico en la Naturalis Historia de Plinio}

En su Naturalis Historia, 6,34 ${ }^{17}$ Plinio el Viejo habla de las Islas Afortunadas aportando un doble testimonio: el del romano Estacio Seboso y el del númida Juba II. De este último refiere lo siguiente:

Iuba de Fortunatis ita inquisiuit: sub meridiem quoque positas esse prope occasum, a Purpurariis DCXXV p., sic ut CCL supra occasum navigetur, dein per CCCLXXV ortus petatur. primam nocari Ombrion, nullis aedificiorum uestigiis; habere in montibus stagnum, arbores similes ferulae, ex quibus aqua exprimatur, e nigris amara, ex candidioribus potui iucunda.

Juba sobre las Afortunadas hizo las siguientes averiguaciones: que están situadas hacia el Sur y casi al Poniente, distando de las Purpurarias 625 millas (unos 920 kilómetros); con tal que se navegue 250 millas hacia el Poniente y luego se viaje en dirección Naciente a lo largo de 875 millas; que la primera isla se llama Ombrio, sin huellas de edificaciones; que tiene en las montañas una charca, árboles semejantes a la férula, de los cuales se extrae agua, amarga de los negros y agradable para beber de los blanquecinos.

${ }^{17}$ Seguimos la edición de Mayhoff (1985). 
A qué planta se está refiriendo Plinio no lo sabemos, pues no es la férula propiamente dicha o ferula communis, sino unos árboles o más bien arbustos semejantes a ella. La férula es una planta que, entre otros detalles, tiene unos tallos erguidos de forma cilíndrica y que pueden tener un grosor de unos $2 \mathrm{~cm}$, con lo cual no es extraño que se pueda sacar de ellos jugo machacándolos. Pero, en cualquier caso, no se trata de esta planta, sino de otra parecida a ella.

En cuanto a la identificación de la isla en donde se crían estas plantas no hay unanimidad, como puede leerse en Álvarez Delgado (1945: 17 y ss.) y en Díaz Tejera (1988: 24-25). Ellos piensan que Ombrio es la isla que actualmente se llama Gran Salvaje ${ }^{18}$ (del archipiélago de las Salvajes, a $165 \mathrm{Kms}$. de las Canarias), pero en esta isla no hay nada parecido a los dos tipos de plantas, así como tampoco en ninguna de las Canarias. Álvarez Delgado (1945: 23) cree que el relato de Mela (dos tipos de fuentes) y el de Plinio (dos tipos de árboles) es la distinta interpretación de un mismo fenómeno que, según él, tiene un origen común, pues si bien ni Plinio copia a Mela, ni este a aquel, ambos tienen una fuente común o, mejor, Mela en este caso bebió de donde mismo lo hizo Juba II -que es la fuente de Plinio-, a no ser que fueran los emisarios que el rey númida envió a recorrer las Afortunadas los que le llevaran el mensaje de los dos tipos de plantas.

Desde luego, según relata Diogo Gomes de Cintra lo único que encontraron las carabelas del Infante Enrique el Navegante en la «Ilha Salvagem» en el siglo XV fue una hierba en gran abundancia que denominó «ursella ${ }^{19}$ y servía para teñir, pero nada más: ni gente, ni árboles, ni ríos; en una palabra, era tan estéril, que ni cabras tenía, de tal modo que el Infante tuvo que mandar allí cabras y machos cabríos para que se reprodujeran ${ }^{20}$.

Asimismo los grandes exégetas y comentaristas del s. XVII se interesaron por saber no solo cuál es la isla sino también por identificar el tipo de planta a que Plinio hace alusión aquí. Como ejemplo de ello veamos el comentario que el ya mencionado Isaac Voss hace al pasaje de Pomponio Mela que citamos más arriba:

$\mathrm{Vt}^{21}$ singulari duorum fontium ingenio maxime insignis] Plinius ex Iuba meminit quidem fontis in insulis Fortunatis, uerum diuersae uirtutis. De Ombrio insula scribit:

\footnotetext{
${ }^{18}$ No así otros, por ejemplo, Stéphane Gsell, cuya opinión es: Ombrios (appellée Pluvialia) est l'île qui se nomme aujourd'hui Lanzarote (Gsell, 1928: 257).

${ }^{19}$ Literalmente esta palabra es un diminutivo de ursa ('osa'), es decir, 'cachorro de osa'.

${ }^{20}$ Die quadam ueniens ego Dioguo ultima uice de Guinea in medio inter insulas de Canaria et insulam de Madeyra uidi insulam, et fui in ea, quae uocatur "Ilha Salvagem». Et est sterilis, et nullus habitat in et (sic), nec habet arbores nec flumina. Istam insulam inuenerunt carauelae D. Infantis. Et uenientes in terram inuenerunt multam "ursellam", quod est quaedam herba, quae tingit rubeum colorem seu pannum, et erat ibi in habundantia magna. Et aliqui postea rogauerunt D. Infantem, ut iis daret licentiam ut irent illuc cum suis carauelis, et illam "ursellam» deferri possent ad "Angliam " et "Flandriam", ubi ualet multum. Et D. Infans dedit eis licentiam, ut ei darent quintam partem de lucro, quem facerent. Et D. Infans misit ibi capras, masculos et femellas, quae creuerunt magna multitudine (Schmeller, 1847: líneas 114-126).

${ }^{21} V t$ en lugar de Vna dice el texto de nuestra cita.
} 
habere in montibus stagnum, arbores similes ferulae, ex quibus aqua exprimatur, ex nigris amara, ex candidioribus potui iucunda. Salmasius et alii de cannis saccharinis haec Iubae uerba accipienda esse contendunt; nempe quia saccharum in insula Madera prouenit. Sed olim aliter fuit; una perpetuaque fuit sylua tota haec insula, eaque densa ac imperuia. Lusitani flammas admouerunt; hinc insecutum septem annorum incendium. Sic demum patefacta terra, sacchariferas cannas intulere Lusitani. In aliis tamen Fortunatis saccharum, ante Hispanorum aduentum, prouenisse non negauerim, praesertim in illa quae dicitur Canaria magna. Sed nequaquam de saccharo accipi posse hunc Iubae locum, libenter, utputo, admittet, qui uel aliquid saltem inaudierit de famosa illa arbore in Ferro insula, cuius stillatitia aqua uniuersis sufficit insulanis, quamuis unica sit. Est illa in summitate montis, e medio surgit stagno, est generis ferulacei, potum uero praestat iucundissimum. Olim, ut uidetur, solitaria non fuit, sed uerisimile est insulanos succidisse ceteras, cum una sufficeret (Ad Pomp. Melam, lib. III, cap. X, p. 603) ${ }^{22}$.

Plinio partiendo de Juba recuerda ciertamente una fuente en las Islas Afortunadas, pero de diversa naturaleza. Sobre la isla de Ombrio escribe «que tiene una charca en las montañas, árboles semejantes a la férula, de los que se saca agua, de los negros amarga, de los blanquecinos agradable para beber». Salmasio y otros discuten que estas palabras de Juba hay que tomarlas referidas a las cañas azucareras; pues, en efecto, la caña se cría en la isla de Madeira. Pero en otro tiempo fue de otra manera; esta isla fue completamente un bosque perenne, y fue toda espesa e inaccesible. Los portugueses le pegaron fuego, y a partir de este momento siguió un incendio que duró siete años. Cuando de este modo finalmente la tierra quedó despejada, los portugueses introdujeron las cañas sacaríferas. Con todo, no me atrevería a negar que en las otras Islas Afortunadas se hubiera criado la caña de azúcar antes de la llegada de los españoles, principalmente en la que se llama Gran Canaria. Pero de ningún modo que este pasaje de Juba pueda referirse a la caña de azúcar, según pienso, lo admitirá con mucho gusto al menos quien haya oído siquiera algo sobre aquel famoso árbol en la isla de El Hierro, con cuyo goteo hay suficiente agua para todos los habitantes de la isla, aunque sea uno solo. Está en la parte más alta de una montaña, se eleva en medio de una charca, es del género feruláceo, pero suministra un líquido muy agradable. En otro tiempo, según parece, no fue único, sino que es verosímil que los isleños cortaron los demás puesto que con uno tenían suficiente.

Además del sintagma aquí utilizado, el tipo de caña al que se está refiriendo Voss tiene varias denominaciones: Arundo saccharifera, arundo saccharina, calamus saccharinus. Sería el Saccharum officinarum (caña dulce) de Linneo. El botánico y médico suizo del s. XVI Gaspar Bauhin (1560-1624) le dedica varios capítulos de

${ }_{22}$ Pomponii Melae De situ orbis libri III, cum notis integris Hermolai Barbari, Petri Ioannis Olivarii, Fredenandi Nonii Pintiani, Petri Ciacconii, Andreae Schotti, Isaci Vossii et Iacobi Gronovii. Accedunt Iulii Honorii oratoris excerpta Cosmographiae. Cosmographia falso Aethicum Auctorem praeferens cum variis lectionibus ex ms. Ravennatis Anonymi Geographia ex ms. Leidensi suppleta. Curante Abrahamo Gronovio. Lugduni Batavorum; ex officina Samuelis Luchtmans, MDCCXXII. 
su obra póstuma ${ }^{23}$. Nos ha llamado la atención el capítulo VI, que él titula De saccharo cando, en donde expone que hay dos tipos de productos que se extraen de la mencionada caña, uno «natural» y otro "preparado». Nos interesa el "preparado», puesto que trata de dos tipos de jugos, uno blanco, y el otro tirando a rojo, que, en parte, recuerdan, mutatis mutandis, los dos tipos de líquidos de los que venimos hablando:

Hoc duplex: alterum Crystallo albo puroque simile, quod Veneti ex Saccharo finissimo parant: sed rectius e Maderensi, uel Canario conficitur: siquidem Finissimum a lixiuio ex calce parato, aliam qualitatem adsciscat, cum etiam quod ex Maderensi, uel Cannario (sic) fit, illud dulcedine superet et candore aequet. Alterum subrufum est, quod nunquam clarum redditur, quod ex Saccharo Thomaeo conficitur. Album praefertur, non solum quod natiuo colore simile sit et dentibus subiectum salis modo frietur, uerum id et uiribus aequet, ipsiusque usus sit in iisdem morbis in quibus eo ueteres usi sunt. (p. 314)

Este es doble: uno semejante al cristal blanco y puro, que los vénetos preparan de la caña más fina, pero se confecciona mejor con la de Madeira o canaria. Ya que el más fino sacado de ceniza preparada a partir de la cal añade otra cualidad, como también el que se hace de la de Madeira o Canarias supera a aquel en dulzura y lo iguala en blancura. El otro es algo rojo, que nunca se vuelve claro, el cual se hace de la caña de Santo Tomé. Se prefiere el blanco no solo porque es semejante al color original y apretado con los dientes se tritura a modo de sal, sino también lo iguala en propiedades, y su uso es en las mismas enfermedades en las que los antiguos usaron de él.

Nos queda señalar, por último, otra opinión, a saber, la posibilidad de que se tratara de una planta del género Euphorbia: «Es posible ... que Plinio tuviera como punto de partida la realidad de los dos tipos de euforbios, uno medicinal y otro amargo y venenoso...», afirma Díaz Tejera (1988: 32). Esta mata lleva el nombre de Euforbo, médico personal de Juba II.

\subsubsection{El tópico en De mirabilibus Mundi de Cayo Julio Solino}

Como sabemos, Solino tuvo muy en cuenta la obra de Plinio y de Pomponio Mela para redactar su Collectanea rerum memorabilium o De mirabilibus Mundi. Por eso no es de extrañar la coincidencia en muchas de sus descripciones. Tal sucede en el pasaje que nos ocupa, en donde grosso modo parece que es Plinio el que habla, como podemos leer en la edición de Panckoucke, p. 5724:

${ }^{23}$ Caspari Bavhini, viri clariss., Theatri botanici sive historiae plantarum ex veterum et recentiorum placitis propria observatione concinnata liber primus editus opera et cura Io. Casp. Bavhini, Basileae 1658.

${ }^{24}$ Nos referimos a la edición de la «Bibliothèque Latin-française» hecha por el editor C.L.F. Panckoucke, acompañada de la traducción al francés de M. A. Agnant, C. Julius Solin, Polyhistor, París 1847. La hemos seguido precisamente por el nombre Norion que da a la isla. 
In prima earum, cui nomen Norion, aedificia nec sunt nec fuerunt. Iuga montium stagnis madescunt. Ferulae ibi surgunt ad arboris magnitudinem: quae nigrae sunt, expressae liquorem reddunt amarissimum; quae candidae, aquas reuomunt etiam potui accomodatas.

En la primera de ellas, que se llama Norion, ni hay edificaciones ni las ha habido. La parte alta de las montañas se humedecen con charcas. Allí las férulas crecen hasta el tamaño de un árbol: las que son negras, una vez exprimidas dan un líquido muy amargo; las que son blancas expulsan aguas incluso apropiadas para beber.

Respecto a «Norion», el nombre de la isla aceptado aquí por el editor, tenemos que señalar que Th. Mommsen en la 2a edición de 1895 utiliza la palabra "Embrion» y en el aparato crítico (Mommsen 1895: 213) hace todo un estudio exhaustivo de las distintas denominaciones para esta isla que aparecen en los distintos manuscritos y ediciones.

Hay una diferencia respecto a Plinio en cuanto a las plantas que producen los dos tipos de jugos: Julio Solino le da, sin más, el nombre de ferulae y dice que crecen hasta el tamaño de un árbol grande (ad arboris magnitudinem), mientras que Plinio no hablaba de ferulae sino de unos árboles semejantes a la férula (arbores similes ferulae). Así, Solino tiene claro el nombre del árbol, al contrario que Plinio, cuya denominación desconoce y, por eso, nos dice que se asemeja a la férula. Solino o es más atrevido o conoció otro manuscrito de Plinio desconocido para nosotros en el que aparecía claramente tal denominación.

\subsubsection{El tópico en el islario de Domenico Silvestri}

Este autor florentino del s. XIV escribió una obra titulada De insulis et earum proprietatibus, en la que va tratando de unas novecientas islas por orden alfabético como si fuera un catálogo o diccionario. En dos ocasiones habla de la isla Embriona y de sus dos tipos de líquido. En el apartado de la letra E está el primer texto que nos interesa:

Embriona insula una ex Fortunatis insulis de quibus infra, in occiduo oceano posita est in qua edifitia nec sunt nec usque ad tempus Plinii non fuerunt. Iuga montium stagnis madescunt, quoddam genus herbarum in modum arundinum quas ferulas uocant ibidem excrescere ad arborum magnitudinem, quarum alique nigre, albe sunt alique, ex nigris sucus et liquor amarissimus manat, ex albis uero dulcis et gustum potus accomodus $5^{25}$.

Embriona, una de las islas Afortunadas sobre las que hablaremos más abajo, está situada en el Océano Occidental, en la que no hay edificaciones, ni las hubo hasta los tiempos de Plinio. Las partes altas de las montañas se mojan gracias a unas charcas;

\footnotetext{
${ }^{25}$ Pecoraro, 1964: 104.
} 
un espécimen de matas del tipo de las cañas del tamaño de los árboles que llaman férulas, se cría allí: de estas algunas son negras, algunas blancas: de las negras sale un jugo y líquido muy amargo, de las blancas, en cambio, una bebida dulce y agradable al paladar.

El segundo texto está en la entrada de Fortunatae insulae, pues ahí vuelve a mencionar a la isla Embriona junto al resto de las Afortunadas, es decir, junto a las otras cinco, y además de decir sobre ella algunas cosas distintas, utiliza otros giros gramaticales, como se ve en el siguiente texto:

Quarum, ut refert Solinus, sex nominibus narrantur: Embriona scilicet, nullis edifitiorum uestigiis, ut Plinius scribit, et huius in montibus esse stagnum cum arboribus similibus ferule ex quibus aqua exprimitur, e nigris amara, ex candidioribus potui iucunda.

De las que, como refiere Solino, se mencionan seis nombres, a saber: Embriona sin huella de edificaciones, según escribe Plinio, y en las montañas de esta hay una charca con árboles semejantes a la férula, de los que exprimidos se saca agua, de los negros amarga, de los que son algo cándidos agradable al paladar.

Tenemos que observar que Silvestri ya no utiliza aquí la palabra herba para denominar la planta, sino arbor, tampoco usa el verbo manare sino exprimere. el primero da la sensación de que el líquido sale espontáneamente de la planta, en cambio el segundo exige un proceso para obtenerlo; y, además, se decanta por la naturaleza del líquido, pues antes hablaba de sucus et liquor, y ahora ya dice que es aqua. Tampoco utiliza el adjetivo dulcis para definir el agua que sale de los árboles cándidos.

Como podemos observar, Silvestri se mueve en la misma línea del ya clásico Plinio el Viejo, a quien toma como punto de referencia y como testigo de que hasta su época no hubo edificaciones en esta isla que, como él, incluye entre las Fortunatae, pero lo hace a través de Solino, sobre todo cuando trata el fenómeno en la entrada de las Fortunatae insulae. Pero, en definitiva, este autor no aporta nada nuevo para identificar la naturaleza de la planta.

\subsubsection{El tópico en Opus de rebus Hispaniae memorabilibus}

Lucio Marineo Sículo (1444-1536), que fue cronista del rey Fernando el Católico, escribió una historia de los hechos memorables dividido en veinticinco $\operatorname{libros}^{26}$. En una parte del relato de lo que hicieron los Reyes Católicos trata sobre las Islas Canarias (De Canariis insulis acquisitis) y, después de hablar sobre el envío de tropas al mando de Pedro de Vera y las batallas con los nativos, dice (fol. 106v.):

${ }^{26}$ L. Marinei Siculi regii historiographi Opus de rebus Hispaniae memorabilibus modo castigatum atque Caesareae maiestatis iussu in lucem aeditum Luca Marineo, Alcalá de Henares 1533. 
Ceterum sunt in Atlantico mari insulae, quas Plinius et alii scriptores Fortunatas appellant, numero septem. Quas rem non ingratam facturus uideor, si nominatim recensuero. Obrion, quam Plinius uocat Ombrium, sine ullis aedificiorum uestigis, quae stagnum habet in montibus, et arbores ferulae similes. Ex quibus aqua exprimit, ex nigris amara, ex candidis dulcis potuique iucunda.

Por lo demás, hay en el mar Atlántico unas islas, que Plinio y otros escritores llaman Afortunadas, en número de siete. Me parece que voy a hacer una tarea grata si les paso revista por su nombre: Obrion, a la que Plinio llama Ombrio, sin huella de edificaciones, que tiene una charca en las montañas y unos árboles semejantes a la férula. De estos sale agua una vez exprimidos, de los negros amarga, de los blancos dulce y grata para beber.

Casi nada nuevo respecto a los anteriores, a no ser el nombre que da a la isla: dice Marineo Sículo que se llama Obrion, pero que Plinio la llama Ombrium. A primera vista podría parecer una errata del autor o editor, pero puesto que recalca su propuesta de nombre frente al que él dice que le da Plinio, tenemos que concluir que pensó que era tal el nombre verdadero, probablemente porque la fuente de donde bebió llevaba ese nombre quizás, en este caso, sí fruto de una errata, pues casualmente la palabra que él utiliza (Obrion) es la misma que, según hemos visto, aparece en Plinio, solo que le falta la nasal labial.

\subsection{El tópico de las islas de SAN BREndÁN}

El santo abad irlandés que, según cuenta la leyenda, recorrió el Océano buscando el Paraíso, visitó en su periplo de siete años numerosas islas en algunas de las cuales aparecen muchas fuentes y ríos con propiedades. A veces en un mismo lugar se nos habla expresa o tácitamente de dos fuentes cuyas aguas tienen propiedades contradictorias u opuestas. Veamos en la Nauigatio Sancti Brendani, texto en el que se plasmó esta odisea oceánica, diferentes islas en las que hemos encontrado alusiones al tema que nos ocupa.

\subsubsection{El tópico en la Isla de las Aves}

Aunque no lo dice expresamente el texto que se nos ha conservado de la Nauigatio $^{27}$, se deduce que en la "Isla de las Aves» había dos fuentes con propiedades mágicas, una positiva de agua excelente, que incluso era capaz no solo de saciar la sed sino incluso de alimentar, y otra negativa de un agua «fuerte de beber» nada recomendable.

${ }^{27}$ Los textos latinos de la Nauigatio los hemos tomado de Selmer (1959). 
La primera era el naciente de un río por cuya desembocadura sacaron la nave los monjes de Brendán cuando llegaron a la isla, y respecto a ella les dice el santo abad:

Si non habuissemus alia dispendia excepto isto fonte, sufficeret, credo, nobis ad uictum et ad potum ille.

Si no hubiésemos tenido otras vituallas sino esta fuente, ella nos bastaría, así lo creo yo, para comida y bebida $(11,14-15)^{28}$.

Lo relatado sobre esta fuente recuerda lo que cuenta Julio Solino sobre los habitantes de las fuentes del Ganges, que no necesitaban más alimento que los olores de los frutos silvestres que se criaban en sus orillas ${ }^{22}$.

Veremos más abajo que el agua de una fuente que hay en el islote de Pablo el eremita es nutritiva y también sirve como alimento.

Más adelante añade Brendán:

Accipiamus de isto fonte stipendia, quia usque modo non fuit nobis opus nisi ad manus et pedes lauare.

Tomemos de esta fuente las vituallas puesto que hasta ahora no la hemos utilizado sino para lavarnos las manos o los pies $(11,75-77)$.

El propio proveedor -hombre que Dios les enviaba periódicamente con alimentos- les recomendó que antes de abandonar la isla llenaran sus vasijas de agua, es de suponer que fuera de este manantial, para el viaje:

Cum autem simul discubuissent ad prandium, locutus est illis idem uir, dicens: "Restat uobis magnum iter. Accipite de isto fonte uestra uascula plena et panes siccos, quos potestis obseruare in alium annum».

Cuando todos estaban sentados a la mesa para comer, el mismo hombre de Dios les habló diciendo: «Os queda un largo camino. Coged vuestras garrafas llenas del agua de esta fuente y panes secos que podéis conservar hasta otro año» $(11,90-94)$.

Sin embargo, en otra visita anterior el mismo proveedor les había dicho:

Viri fratres, hic habetis sufficienter usque ad diem sanctum Pentecostem, et nolite bibere de isto fonte. Fortis namque est ad bibendum. Dicam uobis naturam illius: Quisquis lez (2006).

${ }^{28}$ Las traducciones al español de los textos de la Nauigatio están tomadas de Hernández Gonzá-

${ }^{29}$ Gangis fontem qui accolunt, nullius ad escam opis indigi, odore uiuunt pomorum siluestrium, longiusque pergentes eadem illa in praesidio gerunt, ut olfactu alantur. Quod si tetriorem spiritum forte traxerint, exanimari eos certum est (Mommsen, 1895: 53). 
biberit ex eo, statim irruet super eum sopor, et non euigilabit usque dum compleantur XXIII horae. Dum manat foras de fonte, habet saporem aquae $e^{30}$ et naturam $(11,80-86)$.

Hermanos, aquí tenéis lo suficiente hasta el día santo de Pentecostés, y no bebáis de esta fuente, pues su agua es fuerte para beber. Os diré sus propiedades: a todo el que beba de ella, al instante le entrará un sopor y no se despertará hasta que hayan pasado 24 horas. Mientras está brotando fuera de la fuente, tiene el sabor del agua y su aspecto.

Igualmente, cuando estaban de nuevo en la isla de las Aves y ya se disponían a navegar hasta la Tierra Prometida, el mismo proveedor se ofrece a acompañarlos y le dice a Brendán:

Ascendite in nauiculam et implete utres ex isto fonte...

Llenad los odres de esa fuente y subid a la navecilla... ${ }^{31}(27,22-23)$.

Lógicamente, añadimos nosotros, no podía tratarse de la misma fuente de la que más adelante y por dos veces $(11,90-94$ y 27,22-23) les recomendaría que llenaran sus garrafas antes de partir de aquella isla. Esta sería, pues, una fuente de propiedades negativas. Habría, por lo tanto, dos fuentes, una con agua incluso nutritiva, y otra con agua nefasta ya que el que la bebía dormía todo un día con su noche.

\subsubsection{El tópico en la isla de la Comunidad de Ailbeo}

Después de partir de la Isla de las Aves, Brendán y sus monjes estuvieron navegando durante tres meses hasta que un día vieron una isla e intentaron buscar un lugar para desembarcar, pero, a pesar de pasar cuarenta días bordeándola no lo encontraban y tuvieron que acudir a la oración y abstinencia.

Cum autem permansissent in crebris orationibu $3^{32}$ per triduum et in abstinentia, apparuit illis portus angustus, tantum unius receptio et apparuerunt illis duo fontes ibidem, unus turbidus et alter clarus. Porro fratres festinabant cum uasculis ad hauriendam aquam. Intuens uir Dei illos ait: "Filioli, nolite peragere illicitam rem sine licentia seniorum qui in hac insula commorantur. Tribuent namque uobis has aquas spontanee quas modo uultis furtim bibere» (12,9-16).

Después de que hubiesen permanecido durante tres días en frecuentes oraciones y en abstinencia, apareció ante ellos un puerto estrecho con capacidad solo para

${ }^{30}$ Hemos preferido no monoptongar el diptongo ae. Igualmente las grafías del fonema /u/ las hemos normalizado escribiendo siempre $u$, excepto en mayúscula, que ponemos $V$.

${ }^{31}$ Respecto a la «histeriología» del pasaje no reflejada en la traducción cf. Hernández González (2006: 82, nota 71).

${ }^{32}$ Mantenemos - $t i$ - en lugar de - $c i$ - de la edición seguida por nosotros. 
una nave, y allí mismo se le presentaron dos fuentes, turbia una y otra clara. Entonces los frailes corrían apresuradamente a sacar agua con cantarillos; cuando el varón de Dios se dio cuenta les dijo: «queridos hijos, no hagáis una cosa ilícita sin el permiso de los ancianos que viven en esta isla, pues espontáneamente os darán estas aguas que vosotros queríais beber a hurtadillas».

En un momento posterior el abad del monasterio de la Comunidad de Ailbeo les explicó a los frailes de Brendán el significado de aquellas dos fuentes con las siguientes palabras:

Abbas quoque hortabatur, cum magna hilaritate fratribus dicens: "Ex hoc fonte quem hodie furtim bibere uoluistis, ex eo modo facite caritatem cum iocundidate et timore Domini. Ex alio fonte turbido quem uidistis lauantur pedes fratrum omni die, quia omni tempore calidus est (12,50-54).

Y el abad exhortaba a los frailes diciendo con mucha alegría: de aquella fuente que hoy quisisteis beber agua furtivamente, de ella haced solo caridad con alegría y temor al Señor. Con el agua de la otra fuente turbia que visteis se lavan los pies de los frailes todos los días, porque está caliente en todo momento.

\subsubsection{El tópico en la isla de la fuente somnífera}

En una ocasión que andaban por el mar se les terminaron las provisiones y al cabo de tres días, cansados por el hambre y la sed, llegaron a una isla en la que encontraron una fuente de agua muy transparente con diversas verduras y raíces a su alrededor y distintas clases de peces que saltaban hasta el mar. Cuando estaban sacando agua para beber, Brendán les dijo:

"Fratres cauete ne supra modum utamini his aquis, ne grauius uexentur corpora uestra". At uero fratres inequaliter diffinitionem uiri Dei considerabant et alii singulos calices bibebant, alii binos ceteri uero ternos in quos irruit sopor trium dierum et noctium, in alios quoque duorum dierum in reliquos uero unius diei et noctis $(13,16-21)$.

Hermanos, tened cuidado de usar esta agua moderadamente para que vuestros cuerpos no se dañen más gravemente, pero los frailes tuvieron en cuenta de distinta manera las advertencias del varón de Dios y unos bebieron una copa cada uno, otros dos y los demás tres cada uno, y a estos les entró un profundo sueño durante tres días con sus tres noches, para los segundos el sueño fue de dos días con dos noches como para los demás de un día y una noche.

Aunque en esta isla no se habla de dos manantiales, se trata de una sola fuente en la que hay que ver las dos propiedades, pues a medida que iban bebiendo agua y cuanto más bebían se iba acrecentando lo negativo: la propiedad somnífera.

\subsubsection{Las fuentes del islote de Pablo el Eremita}

Si bien en este capítulo no se dice expresamente que hubiera dos fuentes en el islote, parece deducirse del texto que sí las había; y aunque no se hable de que sus propiedades fueran antagónicas, lo incluimos aquí, al final del epígrafe dedicado 
a la Nauigatio, porque una de ellas tiene propiedades extraordinarias similares a las ya vistas en una de las fuentes de la isla de las Aves.

En efecto, Brendán y sus monjes llegaron a un islote muy curioso en medio del Océano, ya que aunque era redondo, sus características se asemejaban a un cubo pues "casi medía un estadio ... y tenía lo mismo de ancho y largo que de alto». En él vivía un hombre muy anciano (¡ciento cuarenta años!), Pablo el eremita, que se había alimentado durante sesenta años del agua de una fuente. Les cuenta él a Brendán y a sus compañeros que desde que llegó a aquella roca, una nutria le traía en su boca la comida consistente en un pescado y en sus patitas delanteras un manojito de leña para asarlo; y esto lo estuvo haciendo sin interrupción terciados los días durante treinta años:

Tertiam uero partem piscis manducaui omni die et nibil erat sitis gratia Dei, sed in die dominico egrediebatur foras pauxillum aquae de ista petra unde potui sumere potum et uasculum meum implere ad opus manuum. Post triginta quoque annos inueni istas duas speluncas et istum fontem. Ab ipso uino et postea uixi per sexaginta annos sine nutrimento alterius cibi nisi de hoc fonte. Nonagenarius etenim sum in ista insula, tringinta annos in uictu piscium et sexaginta annos in pastu fontis ipsius... Pergite igitur ad patriam uestram et uobiscum asportate uascula plena de isto fonte. Necesse enim erit uobis quia adhuc restat iter uestrum per quadraginta dies (id est usque) in sabbatum Paschae (26, 71-91).

Cada día comía una tercera parte del pescado y, gracias a Dios, no tenía nada de sed, pero los domingos brotaba un poquito de agua de esta piedra, de donde pude coger para beber y llenar mi vasija con el fin de lavarme las manos. Al cabo de treinta años encontré estas dos grutas y este manantial. De este me alimento y me he alimentado durante sesenta años sin ingerir ningún otro alimento excepto el agua de este manantial. Soy, en efecto, nonagenario en esta isla, durante treinta años me alimenté de pescado y sesenta de agua de ese manantial... Id a vuestra tierra y llevad con vosotros vasijas llenas de agua de este manantial, pues os será necesaria, ya que todavía os queda un camino de cuarenta días...

Está claro que en el islote había una fuente que brotaba de una piedra solo los domingos, que le servía para beber y llenar su vasija para lavarse las manos. Pero, al cabo de treinta años encontró dos grutas y un manantial -es de suponer que fuera distinto de la fuente anterior- del que se alimentaba y que también les va a proporcionar alimento a los monjes de Brendán durante los próximos cuarenta días de navegación. De hecho, cuando se describe la llegada de Brendán al lugar, se dice:

Cum autem uenerabilis pater peruenisset ad summitatem illius insulae, uidit duas speluncas, ostium contra ostium, in latere insulae contra ortum solis, ac fontem paruissimum, rotundum in modum patulae, surgentem de petra ante ostium speluncae ubi miles Christi residebat. At ubi surgebat praedictus fons, statim petra sorbebat illum (26, 22-26).

Cuando el venerable abad llegó a la parte más alta de la isla, vio dos cuevas, puerta con puerta, en la parte oriental de la misma, y un manantial pequeñísimo, redondo, a la manera de un patio de una casa, que brotaba delante de la puerta en donde residía el soldado de Cristo. Mas, cuando brotaba el manantial, al punto la piedra lo absorbía. 


\subsection{El TÓPICO EN DiCUIL}

Este monje irlandés del s. IX escribió una obra titulada Liber de mensura orbis terrae en el año 825, que después de permanecer mucho tiempo oculta en códices, fue editada por vez primera siguiendo el Códice Parisino 4806, del s. X, por Carlos Athanasio Walckenaer en París en el año 1807. Cuatro años más tarde (1811) A. Letronio hizo una nueva edición teniendo en cuenta otros tres códices. Nosotros seguimos aquí la edición de G. Parthey (1870). Como señala nuestro editor, el librito De mensura orbis está repleto de varios nombres de autores, de los que él menciona hasta una treintena, pero Dicuil bebió fundamentalmente de Cayo Julio Solino, quien, como sabemos, se inspiró en Plinio. Así que lo atribuible al monje irlandés es más bien poco. Nos interesa el pasaje en el que habla del tópico de los dos tipos de arbustos de los que se extrae un líquido bueno y un líquido nocivo, como ya hicieron Plinio y Solino.

Habitari etiam dicuntur loca ${ }^{33}$ Aethiopiae adusta Trogoditarum, et Ictiofagorum nam cum $^{34}$... ferula $e^{35}$ surgunt ad arboris magnitudinem, earum quae nigrae $e^{36}$ sunt expressae liquorem reddunt amarissimum, quae candidae ${ }^{37}$ aquas reuomunt ${ }^{38}$ etiam potui accommodatas $(58,5-11)$.

También se dice que los lugares adustos de los Trogoditas e Ictiófagos de Etiopía son habitados, pues cuando... las férulas crecen hasta el tamaño de un árbol: de ellas las que son negras, una vez exprimidas dan un líquido muy amargo; las que son blancas expulsan aguas incluso apropiadas para beber.

En este caso el calco de Solino está claro a partir de ferulae: usa las mismas palabras, lo que ha hecho posible que los editores pudieran corregir las lecturas alteradas de los manuscritos. Julio Solino aplicaba este relato a la isla Norion o Embrion en la $2^{\mathrm{a}}$ ed. de Mommsen, quien precisamente alude a la laguna que hay en el texto. A qué isla lo aplica Dicuil no está claro, pues la laguna no nos permite averiguarlo. En cualquier caso, lo que nos interesa es que el monje irlandés recoge la tradición. Para entender la primera parte del relato de Dicuil, que probablemente no tiene nada

${ }^{33}$ La palabra loca fue añadida por los editores, pues los mss. no la traen.

34 fortasse natum e nationibus apud Solinum; post nam cum lacunam indicauimus; folium excidisse e Solini codice, quo usus est Dicuil monuit Mommsenus ad Solin. pag. 209, innuente iam Letronnio pag. 153. Mommsen dice así: [R]CNH (hi quattuor cum inde pendentibus et Dicuile deficiunt v. 1 in ichthyofagorum nam) $[L] M Q G(B) S A P$ et libri recensiti p. 117 praeter eos qui pendent ex [R]CNH(Mommsen, 1895: 209).

${ }^{35}$ Desde ferulae ... accommodatas coincide con Solino, 56,15.

${ }^{36}$ Los mss. traen magnae, pero preferimos nigrae tal como aparece en Plinio y en Solino.

${ }^{37}$ Nos parece más correcta la lectura candidae de V (Venetus Marcianus. Classis x. cod. LXXXVIII) y de Letr. (A. Letronnius) en lugar de candidas.

${ }^{38}$ Cod. Lam. (Parisiensis Lamonianus 9661) semovunt. 
que ver con la leyenda de los dos tipos de arbustos, es mejor acudir al texto de Solino, que dice lo siguiente: habitari etiam addit Aethiopiae adusta Trogodytarum et Ichthyophagorum nationibus... '(Juba) añade también que los lugares adustos de Etiopía son habitados por los pueblos de los trogoditas y los ictiófagos...'

Probablemente el citado pasaje de Dicuil se esté refiriendo a una de las Fortunatae, pues en todo lo demás está siguiendo el texto de Julio Solino, pero ante la duda hemos hecho un apartado distinto para este autor y no lo hemos incluido en el de las Fortunatae Insulae, como hicimos con los antiguos Plinio, Mela y Solino y con los renacentistas Domenico Silvestri y Lucio Marineo Sículo.

\subsection{El tópico en los historiadores de Canarias: Fray Juan de Abreu Galindo}

En su Historia de la conquista de las siete islas de Canaria escrita probablemente en 1632 (Abreu Galindo, 1977: IX) el franciscano andaluz dice que el capítulo II del libro tercero "trata de las aguas y fuentes que hay en esta isla», es decir, en la isla de La Palma. Dice él que en esta isla, concretamente en Fuencaliente, hay una fuente que tiene dos propiedades contradictorias: en unas ocasiones es potable pero en otras no porque es muy caliente y solo serviría para hacer allí un balneario:

Esta isla de La Palma es falta de aguas porque solamente tiene tres arroyos de que hacer caudal: uno que sale de la Caldera... el otro que va a la villa de San Andrés... y el tercero que viene a la ciudad de Santa Cruz y puerto principal... La parte más estéril de aguas... es la que cae a la banda del Sur; porque, si no es alguna fuente de muy poca agua, no hay otra; y aún de esa no se puede aprovechar todas veces, porque una fuente que nace a la orilla del mar no se pueden aprovechar de ella, si no es de baja mar porque cuando crece, la cubre; y sale tan caliente, que puesta una lapa del mar en el nacimiento de la agua, se despide de la concha. Y salir tan caliente lo causa el minero de azufre por donde pasa el agua. Los naturales antiguos llamaban este término en su lenguaje Tagragito, que es 'agua caliente', donde se podría hacer un tanque cubierto donde se curan muchas y diversas enfermedades, bañándose con él... (Abreu Galindo, 1977: 363-364).

Álvarez Delgado quiere poner en relación este fenómeno maravilloso de que habla el padre fray Abreu Galindo con lo que cuenta Plinio sobre Ombrio, pues según el profesor canario, la realidad de La Palma podría haber sido encajada en cualquiera de las islas, y a Plinio se le ocurrió meterla en la que para él era la primera de las Afortunadas, es decir, Ombrio.

El relato que acabamos de ver recuerda lo que contaba el geógrafo árabe Al-Idrisi cuando describía un lago cercano al río Nilo: decía él que el agua de aquel lago era dulce cuando el Nilo lo inundaba en verano, pero cuando en invierno retrocedía hasta la llegada del verano, podía más el agua de mar y, por lo tanto, se volvía salada ${ }^{39}$.

${ }^{39}$ Nuestra lectura del texto de este geógrafo árabe la hemos hecho en la siguiente traducción latina: Geographia Nubiensis, id est, accuratissima totius Orbis in septem climata diuisi descriptio, continens 


\section{CONCLUSIÓN}

Se puede tener la tentación de caer en el error de creer que los tópicos son algo cerrado, están ya todos definidos y pueden ser reducidos a unas pocas frases, generalmente latinas, que expresan temas también prefijados y también cerrados, tales como, por ejemplo, la aurea mediocritas, el beatus ille, el contemptus mundi, etc. Nosotros aquí nos hemos estado refiriendo a algo nuevo, que no se ajusta en nada a los tópicos literarios tradicionales, a lo que también hemos llamado "tópico», pues no deja de ser topos, es decir, un lugar común o tema recurrente que se repite, como hemos visto, en diferentes obras. Se trata de lo positivo en contraposición con lo negativo, lo bueno frente a lo malo, lo verdadero frente a lo falso, lo real frente a lo imaginario. Más concretamente nos hemos centrado en el líquido elemento, el bueno frente al malo, estudiándolo en unas pocas islas del Océano Atlántico, algunas de ellas imaginarias o "fantasma». Y así hemos visto en un relato de Teopompo un río, Placer, con agua salutífera, frente a otro río, Dolor, con agua perniciosa. En Pomponio Mela una fuente mana agua que produce risa hasta la muerte (agua mala), que solo se cura si se utiliza el agua de la otra fuente (agua buena). En Plinio el Viejo aparece una isla con unos arbustos cuyo líquido, una vez exprimido, es bueno si procede de los blancos, pero amargo (malo) si de los negros; se repite en Julio Solino, Dicuil y otros. En la Navegación de san Brendán nos aparecen islas con manantiales y ríos con aguas de distintas propiedades, que se oponen unas a las otras: un agua que sacia y alimenta frente a otra que se recomienda no beber. En fin, incluso hemos visto esta dualidad -agua potable frente a no potable- en una misma fuente de la isla de La Palma mencionada por un historiador de Canarias, fray Juan de Abreu Galindo.

En este artículo sólo hemos hecho una aproximación al tema sin ánimo de agotarlo, pues sin duda habrá otras islas reales o imaginarias no solo del Océano Atlántico que aparecen en los portulanos y en textos de autores antiguos, medievales y modernos en los que se pueda rastrear algo similar a lo que aquí hemos estudiado.

\section{REFERENCIAS BIBLIOGRÁFICAS}

ABReu Galindo, Juan (1977): Historia de la conquista de las siete islas de Canaria, edición crítica con Introducción, Notas e Índice por Alejandro CiORANEsCu, Goya Ediciones, Santa Cruz de Tenerife.

AlBERT, Simon et al. (2016): «Interactions between sea-level rise and wave exposure on reef island dynamics in the Solomon Islands», Environ. Res. Lett. 11054011 [= Environmental Research Letters 11 (5)].

praesertim exactam uniuersae Asiae et Africae... explicationem. Recens ex arabico in latinum uersa a Gabriele Sionita, Syriacarum et Arabicarum literarum professore atque interprete regio, et Joanne Hesronita earundem regio interprete, Maronitis, Parisiis MDCXIX, p. 103: Atque huius lacus Tennis, cum Nilus inundat tempore aestiuo, dulcescit; cum autem hyberno praeualet aqua maris atque ideo salsa euadit. 
Allen, Thomas William (1962): Homeri Opera [Odyssea], Oxford Classical Texts, Oxford.

Álvarez Delgado, Juan (1945): «Las "Islas Afortunadas" en Plinio», Revista de Historia 69: 26-61.

AvEZAC, Armand D' (1846): Historia de las Islas de África, Imprenta del Fomento (versión castellana por una sociedad literaria), Barcelona.

AZnAR VAllejo, Eduardo (1988): «El capítulo de Canarias en el islario de André Thevet», en Francisco Morales Padrón (coord.), VI Coloquio de Historia Canario-Americana (1984), Cabildo Insular de Gran Canaria, vol. 2, pp. 829-862.

BABCOCK, William Henry (1922): Legendary Islands of the Atlantic. A Study in Medieval Geography, American Geographical Society, Nueva York [Reimpresión Andesite Press, 2017].

Burnet, John (ed.) (1957): Platonis Opera, Oxford University Press, Oxford.

CORTÉs COPETE, Juan Manuel (2006): Claudio Eliano: Historias curiosas, introducción, traducción y notas, Gredos, Madrid.

Díaz Tejera, Alberto (1988): «Las Canarias en la Antigüedad», en Francisco Morales Padrón (ed.), Gran Enciclopedia de España y América. Canarias y América, Espasa-Calpe - Argantonio, Madrid, pp. 13-32.

DilTs, Mervin Robert (ed.) (1974): Claudii Aeliani Varia historia, Teubner, Leipzig.

García y Bellido, Antonio (1967): Las islas atlánticas en el Mundo Antiguo, Universidad Internacional de Canarias, Las Palmas de Gran Canaria.

Gronov, Abraham (1722): Pomponii Melae De situ orbis libri III, S. Luchtmans, Lyon.

GSELL, Stéphane (1928 [ $4^{\mathrm{a}}$ ed.]): Histoire Ancienne de l'Afrique du Nord, tome I: Les conditions du développement historique, les temps primitifs, la colonisation phénicienne et l'empire de Carthage, Hachette, París.

Hernández GonZÁlez, Fremiot (2006): Navegación de San Brendán, Akal, Madrid.

JORGE GODOY, Soraya (1996): Las navegaciones por la costa atlántica africana y las Islas Canarias en la Antigüedad, Dirección General de Patrimonio Histórico, Santa Cruz de Tenerife.

MACEDO, Joaquim José DA COSTA (1843): «Memória em que se pretende provar que os árabes não conhecerão as Canárias antes dos Portugueses», Historia e Memorias da Academia R. das Sciencias de Lisboa, Academia Real das Ciências de Lisboa, 2a Serie, tomo I, parte I, Lisboa, pp. 37-141.

Martínez Hernández, Marcos (1992): Canarias en la Mitología. Historia Mitica del Archipiélago, Centro de la Cultura Popular Canaria, Santa Cruz de Tenerife.

MAYHOFF, Karl (1985): C. Plini Secundi Naturalis historiae libri XXXVII, vol. 1, libri I-VI, Teubner, Stuttgart.

Medina, Pedro DE (1549): Libro de grandezas y cosas memorables de España, D. de Robertis, Sevilla.

MeINEKE, August (ed.) (1887): Strabo, Geographica, Teubner, Leipzig.

Mommsen, Theodor (ed.) (1895): Collectanea rerum memorabilium C. Julii Solini, Weidmann, Berlín [Hay reimpresión en 1999: C. Julii Solini Collectanea rerum memorabilium, Weidmann, Zúrich].

Oldfather, Charles Henry (1989): Diodorus Siculus. Diodorus of Sicily in Twelve Volumes with an English Translation, vol. 4-8., Harvard University Press, Cambridge, Mass.

ParThey, Gustav (1870): Dicuili liber de Mensura Orbis Terrae, Nicolai, Berlín.

Pecoraro, Carmela (ed.) (1954): De insulis et earum proprietatibus, Atti della Accademia di Scienze, Lettere e Arti di Palermo, ser. cuarta, vol. XIV, parte seconda: Lettere, fasc. II, Presso l'Accademia, Palermo. 
SCHMELLER, Johann Andreas (ed.) (1847): Diogo Gomes. De prima inuentione Guineae. De Insulis primo inuentis in mari occeano occidentis et primo de Insulis Fortunatis, que nunc de Canaria uocantur, en «Über Valentim Fernandes Alema und seine Sammlung...», impreso en Abhandlungen der philosophisch-philologische Klasse der Königlichen Bayerischen Akademie der Wissenschaften 4 (3): 1-73 [18-41], Múnich.

SELMER, Carl (1959): Nauigatio Sancti Brendani Abbatis from Early Latin Manuscripts, edited with Introduction and Notes, University of Notre Dame, Nueva York.

Solmsen, Friedrich (ed.) (1970): Hesiodi Theogonia, Opera et Dies, Scutum, Friedrich SolmSEN (ed.); Fragmenta Selecta, R. Merkelbach et M. L. WeSt (eds.), Oxford University Press, Oxford.

TALLACK, Malachy (2016): The Un-Discovered Islands: An Archipelago of Myths and Mysteries, Phantoms and Fakes, Polygon, Edimburgo.

TzschuCKE, Karl Heinrich (ed.) (1806-1807): Pomponii Melae de situ orbis libri tres ad plurimos codices manuscriptos vel denuo vel primum consultos aliorumque editiones recensiti cum notis criticis et exegeticis... Siegfried Leberecht Crusius, Leipzig [7 vols.]. 